\title{
IMPACT OF HOUSEHOLD ECONOMIC FACTORS ON INCOME AND SPECIES DIVERSITY OF KANDYAN HOMEGARDENS
}

\author{
D M A H Senaratne ${ }^{\star}$, N K Batagalle* and H B Kotagama ${ }^{\star \star}$ \\ ${ }^{\star}$ Regional Agriculture Research \& Development Center \\ ** University of Peradeniya, Peradeniya
}

Being a highly popular agricultural land use with lot of promising ecological features, Kandyan Home Gardens (KHGs) have strong economic and social functional relationships with the occupants. Most homegardens have been developed out of long term efforts of household members which often extend to multiple generations. Wide variety and adaptation found in homegardens even within relatively small areas with approximately similar agro climatic and physiographic conditions strongly indicate the high influence of socio economic factors on composition and structure of homegardens. Unless vital socio economic relationships involved with homegardens are properly understood, achieving broad policy objectives could become a difficult task. Therefore this study attempts to investigate some of the socio economic relationships associated with KHGs.

Data collection has been done by conducting a survey in 3 villages in Kandy district using a structured questionnaire. Information related to important physical features of homegardens and socio economic aspects of households have been gathered. Based on the gathered information two multiple regression models have been developed to elaborate on factors influencing the income obtained from homegardens and number of species found in homegardens.

Results show monetary income from the homegarden has shown statistically significant positive relationships with size of land, capital used, family labour and number of species. This indicates that in households with high resource endowments homegardens tend to be more commercially productive. Income from other sources has shown a negative relationship with the income from homegardens. The second model shows some interesting results which has important implications related to bio diversity of the system. Land extent, domestically used subsistent outputs and number of family members has shown positive relationships with number of species found in the homegardens. Capital used has shown a significant negative relationship. This indicates that as the resource management is shifted towards more capital intensive forms from subsistent forms it can lead to reduce the bio diversity of the system. This is a very important implication which should be considered seriously in any policy related to use as homegardens.

We can conclude that as homegarden management orients more towards intensive forms it has the potential to increase the income. However this could lead to deterioration of the species profile of the system. Therefore, the challenge for policy is to find a balance between ecological sustainability and economic viability of the system.

Proceedings of the Third Annual Forestry Symposium 1997 of the Department of Forestry and Environmental Science, University of Sri Jayewardenepura, Sri Lanka 